\title{
KEHIDUPAN SOSIAL DAN EKONOMI MASYARAKAT PESISIR PANTAI BALE BALE NONGSA SEBAGAI TEMPAT WISATA DI BATAM TAHUN 2016-2018
}

\section{SOCIAL AND ECONOMIC LIFE OF COASTAL COMMUNITIES BALE BALE NONGSA BEACH AS A TOURIST PLACE IN BATAM IN 2016-2018}

\author{
Nurfaridah $^{1}$ Arnesih $^{2}$ \\ 1,2(ProdiPendidikan Sejarah, Fkip, Universitas Riau Kepulauan, Indonesia) \\ Inurfar@gmail.com,2arnesih@fkip.unrika.ac.id
}

\begin{abstract}
Abstrak
Penelitian ini membahas tentang kehidupan sosial ekonomi masyarakat pesisir pantai Bale-bale Nongsa sebagai tempat wisata di Batam. Tujuan penelitian ini untuk mendeskripsikan kehidupan sosial dan ekonomi masyarakat pesisir pantai Bale Bale Nongsa sebagai tempat wisata di Batam tahun 2016-2018. Jenis penelitian ini adalah kualitatif dengan metode deskriptif. Penelitian ini dilaksanakan di Pantai Bale-bale Nongsa Batam, sumber data dalam penelitian ada dua yaitu sumber primer dan sumber sekunder. Teknik pengumpulan data dilakukan melalui observasi, wawancara dan dokumentasi. Setelah data terkumpul dianalisis dengan model Miles dan Huberman yaitu reduksi data, penyajian data dan penarikan kesimpulan.

Hasil penelitian menunjukkan bahwa di lihat dari hasil wawancara dari segi kehidupan sosial ekonomi masyarakat pesisir pantai Bale-bale Nongsa dari tahun 2016 hingga 2018 dari segi pendidikan masyarakat sekarang sudah sampai kejenjang yang lebih tinggi yaitu perguruan tinggi, hubungan sosial juga stabil dikarenakan masyarakat saling berbaur antara masyarakat setempat maupun pengunjung yang datang di pantai Bale-bale, dari segi mata pencaharian, pekerjaan serta pendapatan stabil karena masyarakat mempunyai bermacam pekerjaan, dari pemerintahan, swasta bahkan bergantung dengan alam.
\end{abstract}

Kata kunci: kehidupan sosial, ekonomi, pantai bale bale

\begin{abstract}
This study discusses the socio-economic life of the coastal Bale-Bale Nongsa beach as a tourist spot in Batam. The purpose of this study is to describe the social and economic life of the coastal communities of Bale Bale Nongsa as a tourist spot in Batam in 2016-2018.

This type of research is qualitative with descriptive method. This research was carried out at BaleBale Nongsa Beach in Batam, there were two sources of data in the study, namely primary sources and secondary sources. Data collection techniques are carried out through observation, interviews and documentation. After the data collected, it was analyzed by the Miles and Huberman models, namely data reduction, data presentation and conclusion drawing.

The results showed that the results of the interviews in terms of socio-economic life of the BaleBale Nongsa coastal community from 2016 to 2018 in terms of community education had now reached a higher level of higher education, social relations were also stable because the community mingled between local people and visitors who come on the Bale-Bale beach, in terms of livelihoods, jobs and stable income because people have various jobs, from government, the private sector and even depend on nature.
\end{abstract}

Keywords: socio-economic life, Bale-Bale beach, Nongsa Batam. 


\section{PENDAHULUAN}

Provinsi Kepulauan Riau merupakan salah satu provinsi yang terbentuk dalam suasana otonomi daerah. Pembentukan Provinsi Kepulauan Riau merupakan kehendak dari masyarakat yang menginginkan terselenggaranya pemerintah yang efektif dan efisien. Perjuangan yang melelahkan dari para tokoh-tokoh yang memprakarsai pembentukan Provinsi Kepulauan Riau akhirnya membuahkan hasil dengan disahkannya Undang-undang Nomor 25 Tahun 2002 tentang Pembentukan Provinsi Kepulauan Riau pada tanggal 24 September 2002 (Gunawan, 2007: 19).

Salah satu kota di Kepulauan Riau adalah Batam. Batam merupakan sebuah kota industri namun seiring berjalannya waktu Batam berubah menjadi kota pariwisata. Di Batam dan sekitar Batam banyak terdapat pantai, oleh sebab itu banyak wisatawan yang mulai berkunjung ke kota Batam, salah satunya adalah pantai Bale-bale yang terdapat di Nongsa Batam.

Nongsa adalah sebuah kecamatan di Kota Batam, Kepulauan Riau, Indonesia. Kecamatan ini terkenal dengan wisata pantainya. Beberapa pantai wisata yang terkenal antara lain Pantai Nongsa, Pantai Maimun, Pantai Tanjung Bemban, Pantai Sekilak dan Pantai Bale-bale. Kecamatan Nongsa juga memiliki sejumlah resort dan padang golf berstandar internasional yang menjadi tujuan wisatawan domestik dan manca negara.

Pantai Bale-bale merupakan pantai baru dibuka pada tahun 2016 lalu di daerah Nongsa Batam, pantai ini sangat bagus dan menawan untuk orang yang ingin refresing, dipantai ini juga sudah terdapat gazebo dan perlengkapan lain untuk orang yang ingin berkunjung. Keunikan dari pantai ini yaitu terdapat panggung atau pentas serta penari yang akan menyambut pengunjung dengan memberi tari persembahan serta tari kreasi melayu lainnya. Sebagian penari merupakan masyarakat yang bekerja di pantai Bale-bale tersebut.

Untuk memahami lebih jelas bagaimana kehidupan sosial ekonomi masyarakat pesisir pantai Bale-bale, penulis tertarik untuk melakukan penelitian dengan judul tentang "kehidupan sosial dan ekonomi masyarakat pesisir pantai Bale-bale Nongsa sebagai tempat wisata di Batam tahun 2016-2018”. 


\section{METODE PENELITIAN}

Berhubung judul penelitian yang akan penulis teliti adalah tentang kehidupan sosial ekonomi masyarakat pesisir pantai Bale-bale Nongsa sebagai tempat wisata di Batam tahun 2016-2018, maka lokasi penelitian adalah di pantai Bale-bale Nongsa Batam, dan waktu pelaksanaan penelitiannya dilakukan selama tiga bulan dimulai dari bulan Mei hingga Juli 2018.

Teknik pengumpulan data merupakan proses pengumpulan data dengan menggunakan teknik pengumpulan data yang telah ditentukan sejak awal. Proses pengumpulan data sebagaimana diungkap dimuka harus melibatkan sisi aktor (informan), aktivitas, latar, atau konteks terjadinya peristiwa. Sebagai alat pengumpulan data, peneliti harus pandai-pandai mengelola waktu yang dimiliki, menampilkan diri, dan bergaul ditengah-tengah masyarakat yang dijadikan subjek penelitiannya (Idrus, 2009: 148).

Berikut macam-macam teknik pengumpulan data :

\section{a. Observasi}

Teknik observasi merupakan cara mengumpulkan datanya melalui pengamatan langsung ketempat objek penelitian dan melakukan pencatatan terhadap suatu gejala peristiwa yang terjadi di pesisir pantai Bale-bale Nongsa di Batam.

\section{b. Wawancara}

Wawancara merupakan teknik untuk mendapatkan informasi dengan cara mengajukan pertanyaan kepada narasumber. Dalam wawancara penulis akan mengajukan sejumlah pertanyaan secara lisan kepada narasumber yang akan menjadi sumber informasi bagi penulis dalam hal ini adalah masyarakat setempat serta ketua RT dan ketua RW di pesisir pantai Bale-bale Nongsa Batam.

\section{c. Dokumentasi}

Teknik dokumentasi dipakai sebagai cara untuk mengetahui kebenaran atau bukti nyata dari kehidupan sosial ekonomi masyarakat pesisir pantai Bale-bale sebagai tempat wisata di Batam, dengan mengambil gambar atau dokumen tertulis lainnya. 


\section{Teknik Analisis Data}

Analisis terdiri dari tiga alur kegiatan yang terjadi secara bersamaan yaitu: reduksi data, penyajian data, penarikan kesimpulan/verifikasi. Analisis data kualitatif merupakan upaya yang berlanjut, berulang dan terus-menerus. Masalah Reduksi data, penyajian data, dan penarikan kesimpulan/verifikasi menjadi gambaran keberhasilan secara berurutan sebagai rangkaian kegiatan analisis yang saling susul menyusul. Namun dua hal lainnya itu senantiasa merupakan bagian dari lapangan (Miles, 1992: 20).

\section{a. Data Reduction ( Reduksi Data)}

Reduksi data diartikan sebagai proses pemilihan, pemusatan perhatian pada penyerdehanaan, pengabstrakan, dan transformasi data "kasar" yang muncul dari catatan-catatan tertulis di lapangan. Sebagaimana kita ketahui, reduksi data berlangsung terus menerus selama proyek yang berorientasi kualitatif berlangsung. Sebenarnya bahkan sebelum data benar-benar terkumpul, antisipasi akan adanya reduksi data sudah tampak waktu penelitiannya memutuskan (acapkali tanpa disadari sepenuhnya) kerangka konseptual wilayah penelitian, permasalahan penelitian, dan pendekatan pengumpulan data yang mana yang dipilihnya. Selama pengumpulan data berlangsung, terjadilah tahapan reduksi selanjutnya (membuat ringkasan, mengkode, menelusur tema, membuat gugusgugus, membuat partisipasi, menulis memo). Reduksi data/proses transformasi ini berlanjut terus sesudah penelitian lapangan, sampai laporan akhir lengkap tersusun (Miles, 1992: 16).

\section{b. Data display (penyajian data)}

Alur penting yang kedua dari kegiatan analisis adalah penyajian data. kami membatasi suatu "penyajian" sebagai sekumpulan informasi tersusun yang memberi kemungkinan adanya penarikan kesimpulan dan pengambilan tindakan. Beraneka penyajian kita temukan dalam kehidupan sehari-hari mulai dari alat pengukur bensin, surat kabar, sampai layar komputer. Dengan melihat penyajianpenyajian kita akan dapat memahami apa yang sedang terjadi dan apa yang harus dilakukan, lebih jauh menganalisis ataukah mengambil tindakan berdasarkan atas pemahaman yang di dapat dari penyajian-penyajian tersebut (Miles, 1992: 17). 


\section{c. Conclusing Drawing (verification)}

Menurut (Miles dan Huberman, 1992: 19) Langkah ketiga dalam analisis data kualitatif adalah penarikan kesimpulan data verifikasi. Dari permulaan pengumpulan data, seseorang penganalisis kualitatif mulai mencari arti bendabenda mencatat keterarturan, pola-pola, penjelasan, konfigurasi-konfigurasi yang mungkin, alur sebab akibat, dan proposisi. Kesimpulan awal yang dikemukakan masih bersifat sementara, dan akan berubah bila tidak ditemukan buku-buku yang kuat yang mendukung pada tahap pengumpulan data berikutnya, tetapi apabila kesimpulan yang dikemukakan pada tahap awal, didukung oleh bukti-bukti yang valid dan konsisten saat penelitian kembali kelapangan mengumpulkan data, maka kesimpulan yang dikemukakan merupakan kesimpulan yang kredibel. Dengan demikian kesimpulan dalam penelitian kualitatif mungkin dapat menjawab rumusan masalah yang dirumuskan sejak awal, tetapi mungkin juga tidak, karena seperti telah dikemukakan bahwa masalah dan rumusan dalam penelitian kualitatif masih bersifat sementara dan berkembang dilapangan.

\section{HASIL DAN PEMBAHASAN}

Kawasan pantai Bale-bale berada diperkampungan tua sehingga untuk memasuki pantai harus melewati rumah rumah warga, karena lokasinya tepat dibelakang rumah rumah warga tersebut. Walaupun pantainya kecil namun pasirnya putih dan bersih sangat elok dipandang mata, tempat untuk bersantai juga sudah di sediakan. Fasilitas yang disediakan disini berupa lapangan volly, permainan panjat tali, panahan, banana boat, kayak, bahkan boat untuk ke Pulau Putri juga sudah disediakan.

Keunikan dari pantai Bale-bale yaitu adanya tari persembahan budaya melayu yang ditujukan untuk para turis mancanegara yang datang kepantai Balebale, mereka menari diatas panggung yang telah disediakan oleh masyarakat pesisir pantai Bale-bale.

Para penari ini merupakan warga dari masyarakat yang tinggal di pesisir pantai Bale-bale, ada yang masih bersekolah bahkan ibu-ibu rumah tangga. 
Sedangkan turis yang datang dibawa oleh Inko Batam Tour dan Travel yang bekerja sama dengan masyarakat pesisir pantai Bale-bale.

\section{Kehidupan Sosial Ekonomi masyarakat pesisir pantai Bale-bale}

\section{Mata pencaharian}

Masyarakat pesisir pantai Bale-bale bermata mayoritas berpencaharian nelayan, ada juga yang berdinas di pemerintahan, bekerja di perusahaan swasta, namun dikarenakan letak geografis masyarakat di pesisir pantai dan dekat dengan laut, masyarakat cenderung memanfaatkan laut sebagai tempat untuk mencari nafkah oleh sebab itu sebagian besar masyarakat bergantung dengan alam, dan sebagian masyarakat sudah bermata pencaharian di segala bidang, contohnya di pemerintahan dan swasta.

Pantai Bale-bale dijadikan sebagai salah satu obyek wisata di Batam, maka ada perubahan terhadap mata pencaharian masyarakatnya ada juga perubahan masyarakat, sebagian masyarakat terutama kaum perempuan yang sudah menikah sebelumnya hanya ibu rumah tangga, kini mereka memiliki pekerjaan dengan memmanfaatkan lokasi wisata pantai ini, untuk modal jualan mereka dibantu oleh pemerintah daerah dengan di sewakannya stan untuk menjual sovenier dan bermacam barang lainnya, sebagian masyarakat dari segi mata pencarian yang sebelumnya pantai Bale-bale hanya bermata pencaharian sebagai nelayan, bekerja sebagai kedi, dan pekerjaan lainnya, namun setelah adanya pantai Bale-bale mata pencaharian masyarakat ikut berubah, mereka tidak hanya bergantung dengan alam, namun ada yang berpartisipasi dalam membangun pantai Bale-bale dan bekerja di pantai Bale-bale.

\section{Pekerjaan}

sebelum adanya pantai Bale-bale sebagian masyarakat setempat sebelumnya bekerja sebagai Kedi dilapangan golf Palm Spring dan Trinbay. Dan sebagian masyarakat yang bekerja bergantung dengan alam, dikarenakan keadaan geografis yang tinggal dipesisir pantai Bale-bale dengan keadaan alam yang 
mendukung dan dekat dengan laut, oleh karena itu masyarakat yang tidak bersekolah sebagian besar mereka bekerja sebagai nelayan.

Namun dikarenakan masyarakat pesisir pantai Bale-bale sudah ramai penduduk dan bermacam-macam profesi, sebagian masyarakat juga sudah hidup modern karena sebagian masyarakat sudah mencapai pendidikan tinggi.

masyarakat yang tinggal di pesisir pantai Bale-bale bekerja seperti masyarakat lainnya dengan bermacam-macam profesi dan bermacam jenis pekerjaan, dari bekerja di pemerintahan, swasta, bahkan bekerja bergantung dengan alam. Namun setelah pantai Bale-bale menjadi tempat wisata pada tahun 2016, pekerjaan masyarakat juga ikut berubah, dikarenakan faktor-faktor yang mendukung masyarakat dalam mendapatkan pekerjaan. Sebagian masyarakat juga bekerja membuat kerajinan tangan yang bahkan dijual di pesisir pantai Bale-bale, bekerja sebagai pedagang sovenier, bekerja sebagai penari dan bermacam pekerjaan lainnya.

\section{Pendapatan}

Pendapatan masyarakat dipantai Bale-bale tergantung banyak dan tidaknya masyarakat yang berkunjung baik itu masyarakat domestik ataupun mancanegara, setelah adanya pantai Bale-bale menjadi tempat wisata di Batam, ekonomi masyarakat yang sebelumnya hanya pengangguran dapat dibantu, dan pantai Balebale ini dapat menambah pendapatan bagi masyarakat pantai Bale-bale untuk berdagang, namun hasil pendapatan yang didapatkan tergantung banyak dan sedikitnya pengunjung.

\section{Hubungan sosial}

Masyarakat pesisir pantai Bale-bale berhubungan baik dikarenakan masyarakat di pesisir pantai Bale-bale saling berbaur, masyarakat di pesisir pantai Bale-bale juga mempunyai ikatan persaudaraan dan sembilan puluh persen merupakan satu suku yang sama, yaitu suku Bugis Selayar. Masyarakat pesisir pantai Bale-bale dari cara bersopan santun hingga cara berbahasa sudah baik, dikarenakan masyarakat pesisir pantai Bale-bale lumayan ramah terhadap pengunjung, serta sesama 
masyarakat lainnya. Dilihat dari segi pakaian masyarakat juga layaknya seperti masyarakat lain, mereka berpakaian seadanya dan seperti biasanya menggunakan pakaian yang sopan dan tertutup.

\section{Pendidikan}

Masyarakat pesisir yang ada di pantai Bale-bale sangat ramai, tentulah masyarakat pantai Bale-bale sangat membutuhkan penunjang untuk kebutuhan sehari-hari, penunjang kebutuhan yang dimaksud bukan hanya sandang dan pangan saja melainkan juga pendidikan yang sangat penting sebagai kebutuhan hidup yang lebih baik lagi. Berbicara tentang pendidikan, dari tahun 2016 masyarakat pesisir pantai Bale-bale sudah mengeyam pendidikan hingga sekarang.

pendidikan masyarakat di pesisir pantai Bale-bale tergantung bagaimana pendapatan masyarakat di pesisir pantai Bale-bale. Semangat anak-anak kurang dalam berpendidikan, dikarenakan kurangnya biaya yang mencukupi untuk sampai kejenjang yang lebih tinggi. Namun sebaliknya sebagian anak-anak pesisir pantai Bale-bale sudah ada yang mengenyam sampai keperguruan tinggi, tapi sebagian besar hanya tamatan SMP dan SMA.

\section{KESIMPULAN}

1. Di lihat dari hasil observasi keunikan dari pantai Bale-bale Nongsa Batam yaitu adanya panggung serta penari yang memberi persembahan kepada pengunjung yang datang dari mancanegara dan domestik dengan menarikan lagu melayu, karena sebelumnya pantai yang ada di Batam jarang atau bahkan tidak ada yang menggunakan cara seperti ini.

2. Di lihat dari hasil wawancara dari segi kehidupan sosial ekonomi masyarakat pesisir pantai Bale-bale Nongsa yaitu dari pendidikan masyarakat sudah sampai kejenjang yang lebih tinggi yaitu perguruan tinggi, hubungan sosial juga stabil dikarenakan masyarakat saling berbaur, dari segi mata pencaharian, pekerjaan serta pendapatan stabil karena masyarakat mempunyai 
bermacam pekerjaan, dari pemerintahan, swasta bahkan bergantung dengan alam.

\section{SARAN}

1. Bagi pemerintah diperlukan kerja sama yang lebih baik agar dapat memperluas dan menambah fasilitas pantai Bale-bale Nongsa sebagai tempat wisata di Batam, sehingga masyarakat domestik dan mancanegara lebih tertarik untuk berkunjung ke pantai Bale-bale.

2. Bagi mahasiswa khususnya pendidikan sejarah lebih dapat mengangkat sejarah lokal masyarakat asli Kepulauan Riau khususnya yang ada di Nongsa.

3. Bagi pembaca dan kalangan umum agar lebih tertarik untuk berkunjung ke tempat wisata yang ada di Batam, agar masyarakat lebih mengenal kehidupan sosial ekonomi hingga kebudayaan yang ada di Batam.

\section{REFERENSI}

Gunawan, Markus. (2007). Provinsi Kepulauan Riau. Batam: Katalog Dalam Terbitan (KDT).

Hasibuan, Malayu.S.P (2003) Manajemen sumber daya manusia. Jakarta: Bumi aksara

Idrus, Muhammad. (2009). Metode penelitian ilmu sosial. Jakarta: Erlangga

Miles, Matthew B, Dkk. (1992). Analisis data kualitatif. Jakarta: Universitas Indonesia (UI-Press).

Prasetya, J.T ( 2011) Ilmu budaya dasar. Jakarta: Rineka cipta

Ratna, N.K (2010) Metodologi Penelitian. Yogyakarta: Pustaka pelajar

Satria, Arif ( 2009) Pengantar sosiologi masyarakat pesisir.Jakarta: yayasan pustaka obor Indonesia

Satori, Jam'an, Dkk (2007). Metodologi penelitian kualitatif. Bandung: Alfabet

Setiadi, Dkk (2006) Ilmu Sosial Budaya dasar. Jakarta: Kenca prenada Media Group

Supardan, Dadang (2008). Pengantar Ilmu Sosial. Jakarta: Bumi Aksara 
Historia: Jurnal Program Studi Pendidikan Sejarah

Vol 4. No 1 (2019):1-10

P-ISSN 2301-8305

E-ISSN 2599-0063

Soekanto, Suerjono. (2013) Sosiologi Suatu Pengantar. Jakarta: Raja Grafindo persada

Sugiono. (2016) Metode Penelitian. Bnadung: Alfabet 